\title{
Agroecologia: Perspectivas e Desafios para a Agricultura Familiar
}

\section{Agroecology: Prospects and Challenges for Family Agriculture}

\author{
Larisse Medeiros Gonçalves*a; Caroline Viganób; Chaiane Renata Grigoloa; Pedro Henrique da Silva Monteiro; \\ Thiago de Oliveira Vargas ; Wilson Itamar Godoy
}

\author{
${ }^{a}$ Universidade Tecnológica Federal do Paraná, Programa de Pós-Graduação Stricto Sensu em Agronomia. PR, Brasil. \\ bUniversidade Tecnológica Federal do Paraná, Programa de Pós-Graduação Stricto Sensu em Desenvolvimento Regional. PR, Brasil. \\ *E-mail: larisse@alunos.utfpr.edu.br
}

\begin{abstract}
Resumo
Embora a produção sustentável e a agroecologia tenham relevância e vasta quantidade de artigos, há insuficiência de materiais sistemáticos que auxiliem no emprego operativo das características sustentáveis na produção. Esse trabalho traz uma base conceitual que direciona para a sistematização pragmática, no que diz respeito à produção orgânica, por meio de uma revisão bibliográfica. A produção de alimentos em sistemas agroecológicos tem por princípios a adoção de práticas de uso saudável e consciente dos recursos naturais. A produção de orgânicos no Brasil vem apresentando crescimento significativo. Esse avanço está sendo possível devido ao modelo diversificado dos mecanismos de controle de qualidade para produtos de origem ecológica, uma vez que há maior acesso para o registro dos mesmos. Porém, o setor enfrenta várias dificuldades, como problemas de logística, processos burocráticos na certificação e déficit de insumos, além de carência de informações técnicas. Para que tais barreiras sejam superadas, investimentos em pesquisas científicas para aprimorar as técnicas de produção e estratégias de marketing para promoção dos alimentos orgânicos são recursos indispensáveis para o avanço do sistema. Além disso, o governo deve desenvolver políticas para ampliação da produção, oferta e consumo de produtos orgânicos para fortalecer e incentivar tal modelo produtivo.
\end{abstract}

Palavras-chave: Alimentos Orgânicos. Certificação. Sistemas Agroecológicos, Desenvolvimento Rural Sustentável.

\begin{abstract}
Although sustainable production and agroecology have relevance and a vast number of articles, there is a lack of systematic materials that assist in the operational use of sustainable characteristics in production. This work provides a conceptual basis that leads to pragmatic systematization, regarding organic production, through a bibliographic review. The food production in agroecological systems is based on the adoption of healthy and conscious use of natural resources practices. Organic production in Brazil has been showing significant growth. This progress is being made possible due to the diversified model of quality control mechanisms for ecological origin products, since there is greater access to their registration. However, the sector faces several difficulties, such as logistical problems, bureaucratic processes in certification and deficit of inputs, in addition to a lack of technical information. For these barriers to be overcome, investments in scientific research to improve production techniques and marketing strategies for promoting organic food are indispensable resources for the system advancement. In addition, the government must develop policies to expand the production, supply and consumption of organic products to strengthen and encourage such a productive model.
\end{abstract}

Keywords: Organic Food. Certification. Agroecological Systems. Sustainable Rural Development.

\section{Introdução}

O meio ambiente é alterado de forma antrópica por conta das diferentes formas que a sociedade tende a se adaptar, em vários setores. Na produção de alimentos, as condições de modificações baseiam-se nos diferentes paradigmas traçados a partir da sua trajetória histórica. Um exemplo desse fato, está no enfoque de intensa produção e alta lucratividade, que constitui acentuadas transformações do estado natural do ecossistema, levando ao desequilíbrio ambiental, sem construir a consciência da necessidade da resiliência dos recursos naturais e da realidade socioeconômica (WACHTER; REGANOLD, 2014).

Diante desse fato, tem-se na agricultura de base agroecológica uma ferramenta para o desenvolvimento sustentável, pois, a mesma tem como base princípios que impulsionam os ciclos biológicos para manter e melhorar a fertilidade do solo, visto que, o uso exagerado de insumos químicos sintéticos pode tornar os sistemas dependentes. Trazem também, debates acerca de questões climáticas e ambientais, fortalecendo práticas que minimizam formas de poluição, promovendo o uso de controle de pragas e doenças de forma natural, sustentando a diversidade genética do agroecossistema, além de melhorar o rendimento da produção gerenciando a regulação natural dos sistemas produtivos (LESSA, 2015).

Nesse sentindo, a agroecologia pode servir de base para estimular famílias produtoras a se tornarem ecológicas, contribuindo para garantia da segurança alimentar e da autonomia do sistema produtivo, de forma holística. De maneira geral, essa forma de produção, considerada sustentável, vem instigar uma transformação na forma com que os agricultores participam nos processos de produção e inovação de conhecimento, experimentação local novas 
práticas, técnicas e tipos de organização apropriados que se adequem na sua realidade (NYANTAKYI-FRIMPONG et al., 2017; SOUSA et al., 2016).

Para que haja uma suavização dos impactos das atividades humanas sobre os agroecossistemas, deve-se repensar o paradigma atual de produção e pensamento, construindo uma atitude reflexiva afim de edificar limites que fortaleçam a resiliência dos recursos naturais e o desenvolvimento sustentável, reconhecendo as diferentes práticas agrícolas do conhecimento camponês e sua organização social (COOLSAET, 2016; AUBIN, 2017).

Com isso, demonstra-se que apesar da importância de abordar esse assunto existe um déficit de literatura que trazem o tema de maneira objetiva e pragmática. Assim, este artigo tem como objetivo apresentar a importância da agricultura familiar no desenvolvimento da agricultura sustentável, assim como, descrever seus principais obstáculos para a consolidação dessa estratégia produtiva, fortalecendo o debate e a reflexão do que se necessita para o fortalecimento da agroecologia.

\section{Desenvolvimento}

\subsection{Metodologia}

Para a realização deste estudo foi aplicada a metodologia de revisão sistemática, que consiste em aplicar estratégias científicas que limitam o viés da seleção de artigos, para posteriormente sintetizar estudos relevantes em um ou mais tópicos específicos. Os critérios acerca dessa metodologia foram: formulação de tópicos específicos sobre um tema amplo, localização dos estudos, coleta de dados, análise e apresentação dos dados, interpretação dos dados, resultando em aprimoramento e atualização da revisão (BOTELHO et al., 2011).

As buscas foram realizadas nas bases de dados eletrônicas Google Scholar, Science Direct e Elsevier. A amplitude de data dos trabalhos abordados para elaboração dessa pesquisa variou de 2002 a 2020 e é importante ressaltar que artigos com publicação acima de 10 anos são de cunho conceitual fundamentais para dar apoio a pesquisa.

Os descritores utilizados foram: desafios na agroecologia, certificação orgânica, sistemas agroecológicos, desenvolvimento rural sustentável. Foram selecionados 400 artigos com base no título vinculado às palavras-chaves e 46 foram selecionados para discutir o assunto, por demonstrarem maior relevância no enfoque da pesquisa. Para escolha dos artigos, adotou-se os critérios: datas atuais para ensaios práticos, autores que são referência da área, além de analisar detalhadamente se o contexto dos estudos contribuía para o tema proposto, foram excluídos trabalhos repetidos, dissertações, teses e monografias, dando preferência à publicação em periódicos e notas técnicas de intuições certificadoras.

O tema amplo escolhido foi a agroecologia e os tópicos foram subdivididos em perspectivas e desafios. As perspectivas foram a importância para agricultura familiar e a projeções de desenvolvimento e contido no subtopico de desafios se investigou os principais anseios e entraves que travam o fortalecimento da agricultura orgânica agroecológica.

\subsection{Agricultura familiar na base do desenvolvimento sustentável}

Antes de expora recente conceituaçãodeagricultura familiar vale explicitar que esta classificação surge da desintegração, ou melhor citando, da diferenciação do campesinato. Numa perspectiva geral, o campesinato corresponde a uma forma social de produção, cujos fundamentos se encontram no caráter familiar, tanto dos objetivos da atividade produtiva voltados para as necessidades da família - quanto do modo de organização do trabalho, que supõe a cooperação entre os seus membros (WANDERLEY, 2014).

Em um sucinto histórico acerca do termo, Wanderley (2014) destaca que nos anos 1990, a categoria "agricultura familiar" foi adotada pelo próprio estado a partir da formulação do programa de apoio aos agricultores, cuja atividade estivesse organizada pela e para a família (ABRAMOVAY et al., 2010). Nesse sentido consagrou-se não só pelas instituições do estado, mas também pelos próprios atores sociais, seus beneficiários.

Essa classe é também definida levando em consideração pressupostos teóricos e condicionamentos operacionais e se baseou nas concepções adotadas pela Lei da Agricultura Familiar (Art. 3º , Lei n. 11.326/2006), que considera as exigências para caracterizar um produtor, são elas:

Não detenha, a qualquer título, área maior do que 4 (quatro) módulos fiscais; utilize predominantemente mão de obra da própria família nas atividades econômicas do seu estabelecimento ou empreendimento; tenha renda familiar predominantemente originada de atividades econômicas vinculadas ao próprio estabelecimento ou empreendimento; dirija seu estabelecimento ou empreendimento com sua família.

O setor agropecuário familiar tem a característica de ser gerido e manejado pelos próprios integrantes das famílias produtoras e a atividade produtiva agropecuária é a principal fonte geradora de renda. Esse segmento é constituinte da maior parte dos produtores rurais brasileiros (4,4 milhões), que representam $84 \%$ das unidades produtivas rurais no país (MDA, 2017). Portanto, a agricultura familiar tem papel fundamental para fomentar o desenvolvimento brasileiro, visto que, $38 \%$ do valor bruto no setor agropecuário vem desta e corresponde a $70 \%$ dos postos de trabalho camponês. Ainda, a agricultura familiar reflete a produção de mais de 50\% dos alimentos da cesta básica brasileira, com isso, necessita de visibilidade diante a sua significância nas funções econômicas e sociais do país (MDA, 2017; ANDRADE et al., 2016; BERCHIN et al., 2019; BRASIL, 2006)

Sabendo-se que a agricultura familiar é de extrema importância na condução de sistemas mais equilibrados, contribuindo nas diversificações dos agroecossistemas, a FAO 
(2014) afirma que a mesma detém cerca de 75\% dos recursos agrícolas no mundo, produzindo aproximadamente $80 \%$ dos alimentos consumidos. É de extrema importância frisar que as intervenções agrícolas em unidades de produção familiares devem ser estimuladas de maneira sustentável, pois assim, ajudam a garantir a segurança alimentar e a resiliência dos recursos naturais. Diante desse fato, as políticas públicas voltadas para esses atores sociais podem ser estratégias que direcionam ao desenvolvimento rural sustentável.

Ademais, mesmo que se pense que produtores familiares são atores sociais que vivem condições precárias, devese enfatizar que, apesar de terem acesso nulo ou muito limitado ao sistema de crédito, deve-se estimular alternativas inovadoras valorizem as técnicas tradicionais, auxiliando na integração de mercados mais dinâmicos e competitivos. A unidade de produção agrícola familiar, tem peculiaridades que se distinguem de outros empreendimentos familiares, como por exemplo: a estabilidade, a integração com a natureza, a menor vulnerabilidade a conjunturas e a ciclos de crescimento e de extinção, sua capacidade de diferenciar- se e se converter em empresa (BAIARDI; ALENCAR, 2014).

Deve-se considerar que a agricultura familiar está ligada à redemocratização e às categorias sociais no campo que foram agrupadas sob este novo conceito, caracterizado por Neves (2002, p.137) como "uma categoria de ação política que nomeia um amplo e diferenciado segmento mobilizado à construção de novas posições sociais mediante engajamento político".

\subsection{Benefícios da certificação orgânica na promoção da agroecologia}

Ao fortalecer a agricultura orgânica, contribui-se para a manutenção da biodiversidade e, por consequente, o equilíbrio das relações do ecossistema, uma vez que a agricultura que rege em larga escala de maneira convencional produz efeitos negativos sobre estas relações. Terras cultivadas com sistemas de monocultivo, por possuírem objetivo de alta produtividade e rendimento, não ponderam a conservação da biota, uma vez que parte dessa biodiversidade é considerada como pragas que podem trazer prejuízos no rendimento, ao inserir no sistema um produto que as elimine, pode também, contribuir para o desaparecimento de espécies que realizam atividades benéficas para a agricultura, tais como bactérias fixadoras de nitrogênio, polinizadores, fungos micorrizas (BOMMARCO et al., 2013; BOMMARCO et al., 2018; LACOMBE et al.,2018).

Esse crescimento tem se dado pelo maior acesso às informações dos benefícios à saúde que os produtos orgânicos ofertam, bem como, a influência favorável nos biossistemas, associando de maneira harmoniosa a agricultura e a fauna, promovendo crescimento econômico e melhorando a qualidade de vida do agricultor, dos moradores próximos às produções e do consumidor final. Para os autores Diniz et al. (2014), essa nova concepção e consciência de agricultura sustentável pode ter muitos benefícios, como por exemplo:
Auxilia na movimentação dos mercados locais para o escoamento de sua produção, privilegia o consumidor, onde, incita a democratização, popularização e massificação do consumo de produtos ecológicos; reduz a distância entre produtores e consumidores, estimulando relações solidárias entre eles; valorizar os serviços socioambientais gerados; ajudam a impulsionar o compartilhamento de benefícios da comercialização entre todos os envolvidos; promove a cooperação, a transparência e a complementaridade entre os agentes do processo de comercialização; possibilita uma crescente inclusão de agricultores e consumidores no mercado.

Um estudo realizado em algumas regiões da Alemanha demonstrou a diminuição no número de espécies de insetos, cerca de $76 \%$ a $82 \%$ da biomassa desses seres vivos em 20 anos devido ao manejo exaustivo provindo da agricultura convencional (HALLMANN, 2017). A biodiversidade possui um papel funcional dentro de um agroecossistema, o que envolve o controle do microclima, ciclagem de nutrientes, equilíbrio de populações de organismos indesejáveis e desintoxicação de químicos nocivos, regulação de processos hidrológicos, etc. Quando se reduz a biodiversidade, acarretam-se problemas a níveis ambientais e econômicos, como por exemplo, o anseio de manter um monocultivo embasado na utilização de fertilizantes e pesticidas sintéticos, visto que o agroecossistema deixa de ter capacidade de resiliência (VIGANÓ, et al., 2019).

Diante do contexto apresentado, demonstra-se que os sistemas orgânicos agroecológicos contribuem para o fortalecimento da biodiversidade e equilíbrio ambiental, além disso, é importante perceber as dimensões econômica e social, alternativas às flutuações de mercado, além de contemplar aspectos como a segurança alimentar para períodos climáticos ou comerciais críticos (LIMA, 2019). Porém, existem poucas informações que descrevam e sintetizem os efeitos a respeito rendimento das culturas e nos processos bióticos, a longo prazo, por conseguinte, é necessário o interesse de pesquisadores e profissionais agrícolas que possam experimentar e fornecer um feedback acerca dessa temática.

Com isso, deve-se ressaltar que o International Federation of Organic Agriculture Movements afirma que, mundialmente, o número de agricultores orgânicos certificados está em cerca de 2 milhões (IFOAM, 2016). O que chama atenção desse número é que $80 \%$ destes produtores estão situados em países em desenvolvimento, como o Brasil. Inclusive, nosso país já é considerado um nicho em ascensão, pois, a demanda do consumo destes alimentos também vem crescendo. Em 2016, o crescimento foi de $20 \%$, com faturamento estimado de 3 bilhões de reais, sendo a região Sul responsável pela maior incidência de consumo (34\%) de produtos orgânicos (ORGANIS, 2017; LOURENÇO et al., 2017).

O estabelecimento de normas para regularizar a produção, o processamento, a certificação e a comercialização de produtos orgânicos surgiu da necessidade de os consumidores terem segurança quanto à qualidade dos produtos que adquirem. Organis (2017) em um manual de certificação 
orgânica, destaca que existe diferenciação nesses produtos e existem muito motivos a serem considerados para aplicar às práticas orgânicas:

A diferenciação de produtos orgânicos ocorre com base em suas qualidades físicas, decorrentes principalmente da ausência de agrotóxicos e adubos químicos, por exemplo, que estão mais diretamente relacionadas à forma como esses produtos foram produzidos. Estas características embutidas nos produtos orgânicos não podem ser observadas com facilidade no momento da compra. A distância entre consumidores e produtores e a incapacidade de se ter certeza quanto à forma pela qual os produtos orgânicos foram produzidos justificam a necessidade de monitoramento da produção por uma terceira parte, independente. A certificação é, portanto, uma garantia de que produtos rotulados como orgânicos tenham de fato sido produzidos dentro dos padrões da agricultura orgânica. A emissão do selo ou do certificado ajuda a eliminar, ou pelo menos reduzir, a incerteza com relação à qualidade presente nos produtos, oferecendo aos consumidores informações objetivas, que são importantes no momento da compra.

No entanto, para que os produtores fomentem tais práticas, há necessidade de busca pelo processo de certificação, em que incitará os agricultores à aplicação das legislações, procura de conhecimentos variados para garantir a confiança de seus clientes e realização de investimentos.

Outro fator que ajuda no estímulo para certificação é a conscientização dos consumidores, pois, os mesmos devem estar dispostos a pagar mais por produtos certificados, visto que esse "investimento" pode assegurar um procedimento de produção ambientalmente mais amigável e socialmente responsável. Portanto, a promoção que um mercado consumidor com novas práticas (GLASBERGEN, 2018).

\subsection{Certificação orgânica}

Para a International Federation of Organic Agriculture Movements (IFOAM) a agricultura orgânica necessita ser embasada em quatro princípios. O primeiro é a saúde, ou seja, a produção de alimentos de alta qualidade sem o uso de fertilizantes minerais, pesticidas sintéticos, medicamentos para animais e aditivos alimentares. Outro fator que é ressaltado é a ecologia, visto que, essa forma de produção deve conectar os ciclos e equilíbrios na natureza, a partir da ciclagem energética. O terceiro ponto é a justiça, englobando a boa qualidade da vida, fortalecimento da soberania alimentar, minimização da pobreza, a melhoria do bem-estar animal e levar em consideração as gerações futuras. O quarto princípio é a precaução e responsabilidade, que precisam ser aplicadas antes de adotar novas tecnologias para produção, tais como produtos e organismos advindos da engenharia genética (IFOAM, 2018; TUOMISTO et al., 2012; YU et al., 2018).

De acordo com os dados do CNPO/MAPA do início de 2017, existia um total de 4.194 agricultores familiares cadastrados em 316 nas Organizações de Controle Social (OCSs) registradas junto ao MAPA (BRASIL, 2007). Deve-se ressaltar que para o mercado nacional, a aceitação dos produtos orgânicos acontece em algumas redes de supermercados (baseada em critérios distintos e regulamentados individualmente) e circuitos locais de comercialização (em que há um vínculo de confiança entre consumidor e produtor, fundamentada na trajetória histórica ou de reconhecimento de competência técnica em âmbito local). No entanto, para o mercado internacional, a certificação deve ser realizada por organizações certificadores internacionais que atuam no Brasil. O produto considerado filial nacional precisa ser reconhecido por órgãos, como por exemplo, a IFOAM, e possuir aceitação nos mais diversos mercados mundo afora (MORAES; OLIVEIRA, 2017).

A certificação dos produtos orgânicos no Brasil, inicialmente, foi realizada de modo informal por associações e cooperativas de agricultores e consumidores. Nessa modalidade, essas organizações adotavam regulamentos internos para a produção e comercialização de seus produtos e adotavam selos de garantia de qualidade para assegurar ao consumidor produtos de origem orgânica. Mais tarde, com a possibilidade de exportação dos produtos orgânicos para outros países, fez-se necessário a certificação por organizações de engajamento internacional. Desde então, produção, armazenamento e transporte da produção passaram a ser regidas por normativas internacionais (ORMOND et al., 2002).

Diante da situação, o Ministério da Agricultura, Pecuária e Abastecimento (MAPA) estabeleceu pela Instrução Normativa 007/99 de 17 de maio de 1999, normas disciplinares que englobam desde a produção até a certificação do que é produzido, a fim de padronizar o setor (ORMOND et al., 2002).

Mais tarde, o MAPA estabeleceu a Lei 10.831/2003, regulamentada pelo Decreto 6.323/2007, para a certificação de produtos orgânicos. Diante disso, para que os produtores de alimentos de origem orgânica possam ser reconhecidos por tal nomenclatura, estes precisam atender um dos três mecanismos de certificação para garantia da qualidade orgânica: organização de controle social, sistemas participativos de avaliação da conformidade orgânica ou certificação por auditoria (MAPA, 2009).

O mecanismo de organização de controle social é destinado aos agricultores que possuem produção orgânica em menor escala. Nesse método, existe a formação de uma equipe de agricultores familiares, tal qual possui regras que devem ser atendidas pelos integrantes. Uma vez vinculado a esta organização, atendendo os requisitos estabelecidos, o produtor recebe a declaração de registro e pode comercializar seus produtos com selo orgânico de maneira direta ao consumidor, é importante citar que este selo permite que os produtores possam vender seu excedente em feiras (ou direto ao consumidor) e para as compras do governo (PNAE - Programa Nacional de Alimentação Escolar e CONAB Companhia Nacional de Abastecimento (MAPA, 2009).

Redes socioparticipativas entre agricultores definem os sistemas participativos de avaliação da conformidade orgânica. 
Nesse mecanismo, existe participação ativa dos integrantes, os quais têm por princípios a discussão aberta sobre normas e procedimentos, além de troca de conhecimentos e abertura para sugestões. Esse modelo permite que os produtores detenham autonomia sobre seus produtos, sem a interferência de agentes externos (MAPA, 2009).

Deste modelo, os principais selos de certificação presentes no Brasil, citam-se: AAO (Associação de Agricultura Orgânica), ABIO (Associação de Agricultores Biológicos), Fundação Mokiti Okada, Coolméia, Ecocert, IBD (Instituto Biodinâmico), TECPAR (Instituto de Tecnologia do Paraná), IMO (Instituto de Mercado Ecológico), entre outros. Esses selos alegam que o produtor adota criteriosamente as regras das entidades certificadoras à qual está associado e que o produto foi cultivado sobre regras conhecidas e aprovadas (MORAES; OLIVEIRA, 2017).

Outro mecanismo para garantia de qualidade orgânica dos produtos é a certificação por auditoria, cujo mecanismo pode ser realizado tanto por empresas locais quanto internacionais, sendo o método com maior aceitação para certificação, pois se desenvolve por meio de leis nacionais. Porém é mais oneroso, uma vez que gera custos elevados para a certificação (ECOVIDA, 2018; OLIVEIRA, 2011). O Decreto Federal $n^{\circ} 6.323$, de dezembro de 2007, define produtores orgânicos como associações, agricultores individuais, cooperativas, condomínios e outras formas de organização, formais ou informais (BRASIL, 2007). A legislação descreve que os produtores orgânicos devem ter algumas responsabilidades, as quais estão descritas da seguinte forma no Art. $27, \S 1^{\circ}$ do Decreto Federal n ${ }^{\circ}$ 6.323:

I. seguir os regulamentos técnicos; II. Consentir com a realização de auditorias, incluindo as realizadas pelo organismo de avaliação da conformidade orgânica credenciado; III. Fornecer informações precisas e no prazo determinado; IV. Fornecer informações sobre sua participação em outras atividades referentes ao escopo, não incluídas no processo de certificação; e V. informar o organismo de avaliação da conformidade orgânica credenciado sobre quaisquer alterações no seu sistema de produção e comercialização.

A partir das principais modalidades dos sistemas de certificação orgânica existentes é necessário que os agricultores reflitam qual o perfil mais adequado a ser seguido. Moraes e Oliveira (2017) enfatizam que a certificação por auditoria é a mais habitual entre os produtores de larga escala, pois, as tarifas são mais caras. O sistema participativo tem uma abrangência maior para perfis mais diversos, por proporcionar uma solvência maior dos custos e, principalmente, um intenso compartilhamento de saberes entre os agricultores. Já o sistema de controle social é o que melhor se encaixa para o desenho da agricultura familiar, pois, fortalece o desenvolvimento social e econômico e seu processo é burocrático. Entretanto, destacase que estas são somente recomendações e todo produtor interessado neste eixo da agricultura pode utilizar qualquer um dos sistemas de certificação.

O Plano Nacional de Agroecologia e Produção Orgânica
(PLANAPO), lançado pelo Governo Federal no Brasil em 2012, iniciou um novo ciclo para o triênio até o ano de 2019 , ao beneficiar cerca de 678,5 mil agricultores familiares, produtores orgânicos, povos indígenas e comunidades tradicionais, técnicos e extensionistas. É possível que este fato possa vim a desencadear crescimento nesse eixo (DIRETO DA SERRA, 2017).

\subsection{Desafios na produção orgânica para agricultura familiar}

No Brasil, a cadeia da produção orgânica está sendo construída gradualmente (COSTA et al., 2017). Porém, para a expansão da produção de alimentos de origem orgânica no Brasil, vários obstáculos precisam ser encarados, principalmente, para o agricultor familiar. Falta de orientação e planejamento, a mão de obra, carência de pesquisas científicas abordando a agricultura orgânica, limitações financeiras no processo de conversão, estratégias de divulgação e marketing, dificuldades de acesso ao crédito bancário, de certificação e do acompanhamento das requisições são algumas das principais barreiras enfrentadas pelo produtor que adentra nesse modelo de produção de alimentos (MORAIS; OLIVEIRA, 2017).

A certificação é a etapa responsável pelos maiores custos ao produtor que busca a regulamentação da sua atividade, apresentando-se como uma grande dificuldade para quem pretende entrar na cadeia produtiva de alimentos orgânicos. As unidades de produção familiares quando inseridas a um processo de certificação, precisam cumprir alguns requisitos legais que demandam procedimentos de aprendizados e a necessidade de atualização em inovações de tecnologias, muita das vezes por conta da escassez de orientação, esses agricultores não conseguem seguir (MORAES; OLIVEIRA, 2017).

Uma dificuldade encontrada por alguns autores, em relação à implantação de um sistema orgânico é a necessidade de mãode-obra intensiva, pois, embora na agricultura familiar tenha esse fator com abundância, existe uma tendência dos mais jovens saírem da região rural em busca de outras ocupações, ou por conta de estudos/trabalhos, deixando a população no campo mais velha e consequentemente, não conseguindo realizar todas as operações com eficiência (BERK, 2018). A autora enfatiza, que, no entanto, que mesmo que os jovens considerem a agricultura orgânica como oportunidades de melhora de renda no meio rural, esse campo exige da família do agricultor um nível mais elevado de conhecimento, em forma de formação contínua, que fixem a agricultura familiar nas demandas de mercado, sendo este outro empasse.

Pode-se citar como um exemplo prático dessa evasão de jovens que desestrutura o fortalecimento da agricultura familiar em que resulta na desestabilização no ciclo dos conhecimentos tradicionais sustentáveis, um estudo realizado em Vitorino-PR acerca da juventude rural na agricultura familiar, demonstrou que $52 \%$ destes indivíduos não permanecem na área rural, 
pois, eles encontraram oportunidades de se engajar ao mercado urbano e desempenham funções não relacionadas ao campo. Isso acontece por conta da percepção insatisfatória do que significa ser camponês (VIGANÓ et al., 2018).

Em relação às pesquisas científicas, existe um déficit que precisa ser refletido. Yu et al. (2017) explicam que é de extrema importância que pesquisadores da área fortaleçam projetos que tracem e relatem as diferenças reais de qualidade entre alimentos convencionais e orgânicos por meio de análises comparativas, assim como, experimentos que impliquem na produtividade e rendimento, pois, estes fatores também podem fortalecer a agricultura familiar. De acordo com o relatório da FAO (2014), o aumento do rendimento agrícola para responder à necessidade mundial de segurança alimentar e de uma melhor nutrição, a sustentabilidade ambiental para proteger o planeta e para garantir a própria capacidade produtiva e o aumento da produtividade e a diversificação dos meios de subsistência que lhes permita sair da pobreza e da fome são desafios que os agricultores familiares têm de inovar e atentar-se.

Outro fato que limita a ampliação desse eixo de agricultura é o alto custo para a implantação, limitando agricultores com renda menores, que não conseguem crédito para investir na transição agroecológica. Alguns autores também relatam que mesmo que a busca por produtos orgânicos é de nichos de consumidores mais específicos que estão dispostos a pagar um preço maior pelo produto, o fator valor, torna-se uma questão excludente, dificultando a expectativa num livre mercado e uma distribuição de qualidade nutricional mais justa (ORGANIS, 2017; MORAES; OLIVEIRA, 2017). Triches et al. (2016) corroboram que se deve construir estratégias para que haja uma concorrência justa entre os alimentos orgânicos e os alimentos convencionais, no que tange os preços.

Yu et al. (2017) também relatam que é necessária uma reeducação sobre alimentação, incentivando a reflexão e a consciência acerca alimentos orgânicos, importância ecológica e a relevância de contribuir para movimentação do mercado da agricultura familiar. $O$ fator da comunicação também é um quesito que está aquém, e alguns autores enfatizam que faltam estratégias de marketing para que este mercado seja um alvo do consumidor comum, não somente de um nicho específico (DALCIN, 2014; YU et al., 2017).

Um estudo realizado na cidade de Região Fronteira Noroeste do Rio Grande do Sul, acerca dos produtos orgânicos, afirmou que um dos fatores que intervém no consumo de produtos orgânicos pode estar na aparência destes em relação aos convencionais, pois $74 \%$ dos entrevistados concordaram que os primeiros não são tão visualmente atraentes quanto os segundos (ZAMBERLAN, 2008). Porém, o fato de um alimento não possuir uma aparência desejável aos olhos do consumidor não é indicativo de que o produto está inapto ao consumo. Nessa linha de raciocínio, pesquisas apontam que alimentos orgânicos apresentam melhor sabor, além de melhores características nutracêuticas em relação aos convencionais (MENDES; ALVES, 2017).

Ressalta-se que a certificação pode melhorar a prestação de serviços ecossistêmicos e ajudar os consumidores a identificar produtos sustentáveis, apoiados em múltiplas agendas dos objetivos pautado pelo Desenvolvimento Sustentável das Nações Unidas (JAUNG et al., 2019).

\section{Conclusão}

Com base no levantamento bibliográfico, enfatizouse a importância que a agricultura familiar possui diante o processo de consolidação do desenvolvimento produtivo rural sustentável. Constatou-se também benefícios da produção agroecológica como o fortalecimento da biodiversidade dos agroecossistemas, a emancipação da agricultura familiar e a segurança alimentar e nutricional dos consumidores.

As principais dificuldades encontradas foram a falta de orientação e planejamento, a mão de obra, pesquisas científicas, acesso ao crédito, estratégias de divulgação e marketing, burocratização e alto custo para certificação e do acompanhamento das requisições e implicações ambientais negativas.

\section{Referências}

ABRAMOVAY, R.; MAGALHÃES, R.; SCHRODER, M. Representatividade e inovação na governança dos processos participativos: o caso das organizações brasileiras de agricultores familiares. Sociologias, v.12, n.24, p.268-306, 2010. doi: 10.1590/ S1517-45222010000200010

ANDRADE, I. C. de; SILVA, D. B. da; QUEIROZ CALEMAN, S. M. de. Análise da eficácia social de um programa de produção agroecológica destinado a pequenos produtores rurais. Rev. Bras. Gestão Desenvolv. Regional, v.12, n. 2, p.22-43, 2016.

AUBIN, L. O paradigma agroecológico e as crises da sociedade contemporânea: contribuições socioantropológicas na perspectiva da teoria mimética. Desenvolv. Meio Amb., v. 41, p.270-294, 2017. doi: 10.5380/dma.v41i0.51341

BAIARDI, A.; ALENCAR, C. M. M. de. Agricultura familiar, seu interesse acadêmico, sua lógica constitutiva e sua resiliência no Brasil. Rev. Economia Sociol. Rural, v.52, p.45-62, 2014. doi: 10.1590/S0103-20032014000600003

BERK, A. Fatores que afetam a saída de jovens agricultores de propriedades rurais na Turquia: o caso da província de Niğde. Ciênc. Rural, v.48, n. 8, p.1-8, 2018.

BERCHIN, I. I. et al. The contributions of public policies for strengthening family farming and increasing food security: the case of Brazil. Land Use Policy, v.82, p.573-584, 2019. doi: 10.1016/j.landusepol.2018.12.043

BOMMARCO, R.; KLEIJN, D.; POTTS, S. G. Ecological intensification: harnessing ecosystem services for food security. Trends Ecol. Evolution, v.28, n.4, p.230-238. 2013. doi: 10.1016/j. tree.2012.10.012

BOMMARCO, R.; VICO, G.; HALLIN, S. Explorar os serviços ecossistêmicos na agricultura para aumentar a segurança alimentar. Global Food Security, v. 17, p. 57-63. 2018.

BOTELHO, L. L. R.; DE ALMEIDA CUNHA, C. C.; MACEDO, M. O método da revisão integrativa nos estudos organizacionais. Gestão Soc., v. 5, n. 11, p. 121-136, 2011.

BRASIL. Decreto Federal 6.323, de 27 de dezembro de 2007: 
Regulamenta a Lei no 10.831 , de 23 de dezembro de 2003, que dispõe sobre a agricultura orgânica, e dá outras providências.

BRASIL. Lei $n^{\circ} 11.326$, de 24 de julho de 2006. Estabelece as diretrizes para a formulação da Política Nacional da Agricultura Familiar e Empreendimentos Familiares Rurais. Diário Oficial \{da República Federativa do Brasil\}, 2006.

BRASIL. Ministério da Agricultura, Pecuária e Abastecimento. Produtos orgânicos: o olho do consumidor. Brasília: MAPA, 2009.

COOLSAET, B. Towards an agroecology of knowledges: Recognition, cognitive justice and farmers' autonomy in France. J. Rural Studies, v.47, p.165-171, 2016. doi: 10.1016/j. jrurstud.2016.07.012

COSTA, M. B. B. et al. Agroecology development in Brazil between 1970 and 2015. Agroecol. Sustainable Food Syst., v. 41, n. 3-4, p. 276-295, 2017.

DALCIN, D. et al. Organic products in Brazil: from an ideological orientation to a market choice. British Food J., v. 116, n. 12, p. 1998-2015. 2014. doi: 10.1108/BFJ-01-2013-0008

DINIZ, J.; ÁVILA, M.; NOGUEIRA, M. DOSSIE: Inovações para a valorização de produtos da agricultura familiar e do agroextrativismo no contexto do Cerrado. Sustentab. Debate, v.5, n. 3, p. 16-18. 2014.

DIRETO DA SERRA -ORGÂNICOS (São Paulo). Secretaria especial de agricultura familiar e do desenvolvimento agrário (comp.).Alimentosorgânicos:Brasildeveráterrecordedeprodução em 2017. 2017. Disponível em: <http://www.diretodaserra. com.br/noticias/alimentos-organicos-brasil-devera-te-recordede-producao-em-2017.html >.Acessado em: 10 jan. 2020.

ECOVIDA. Histórico de participação da rede no marco regulatório da Lei Federal. 2018. Disponível em $<$ http://ecovida. org.br/certificacao/>. Acesso em: 20 jan. 20209.

FAO, Ifad. The state of food insecurity in the world, p. 80. 2014.

GLASBERGEN, P. Smallholders do not eat certificates on global sustainability standards and local practices in Indonesia. Ecological Economics, v.147, p.243-252, 2018.

HALLMANN, C. A. et al. More than 75 percent decline over 27 years in total flying insect biomass in protected areas. PloS One, v.12, n.10, p.809. 2017. doi: 10.1371/journal.pone.0185809

IFOAM. International Federation of Organic Agriculture Movements. Principles of Organic Agriculture. Preamble, In: Movement, I.F.O.O.A. (Ed.). 2016.

IFOAM. International Federation of Organic Agriculture Movements. Growth continues: 43.7 million hectares of organic agricultural land worldwide. 2018. Disponível em: <http://www. ifoam.bio/sites/default/files/press-releaseworld-2016-english.pdf >. Acesso em: 18 jun. 2020.

JAUNG, W.; PUTZEL, L.; NAITO, D. Can ecosystem services certification enhance brand competitiveness of certified products? Sustainable Prod. Consumption, v.18, p.53-62, 2019. doi: 10.1016/j.spc.2018.12.003

LACOMBE, C.; COUIX, N.; HAZARD, L. Designing agroecological farming systems with farmers: a review. Agricultural Syst., v.165, p.208-220, 2018. doi: 10.1016/j. spc.2018.12.003

LESSA, A. Agroecologia, participação social e desenvolvimento sustentável. Rev. Políticas Públicas, v.4, n.1/2, p.51-70, 2015.

LIMA, F.A.X. Construction of networks and agroecology: the role of social actors in rural development. Interações (Campo Grande), v. 20, n. 1, p. 171-183, 2019.
LOURENÇO, A. V.; SCHNEIDER, S.; GAZOLLA, M. A agricultura orgânica no Brasil: um perfil a partir do censo agropecuário 2006. Extensão Rural, v.24, n.1, p.42-61. 2017. doi: $10.5902 / 2318179624514$

MINISTÉRIO DO DESENVOLVIMENTO AGRÁRIO. Plano safra da agricultura familiar 2017-2020: Fortalecer o campo para desenvolver o Brasil. Secretaria Especial de agricultura familiar e do desenvolvimento agrário. Disponível em: $<\mathrm{http}: / \mathrm{www}$. mda.gov.br/sitemda/sites/sitemda/files/user_img_1684/3Baixa Cartilha_Plano_Safra_2017.pdf. > Acesso em: 10 jan. 2020.

MENDES, D; ALVES, G. Produção orgânica: os caminhos e as dificuldades de uma alimentação mais saudável. 2017. Disponível em: <https://acifaacunesp.com/2017/09/15/producaoorganica-os-caminhos-e-as-dificuldades-de-uma-alimentacaomais-saudavel/. > Acesso em 25 de janeiro de 2019.

MORAES, M. D. de; OLIVEIRA, N. A. M.de. Produção orgânica e agricultura familiar: obstáculos e oportunidades. Desenvolv. Soc. Debate, v.3, n.1, p.19-37, 2017. doi: 10.18616/rdsd.v3i1.3372

NEVES, D. P. A agricultura familiar e o claudicante quadro institucional. In: LOPES, E.S.A.; MOTA, D.M.; SILVA, T.E.M. (Org.). Ensaios: desenvolvimento rural e transformações na agricultura. Aracaju: Embrapa Tabuleiros Costeiros, Universidade Federal de Sergipe, 2002.

NYANTAKYI-FRIMPONG, H. et al. Agroecology and healthy food systems in semi-humid tropical Africa: Participatory research with vulnerable farming households in Malawi. Acta tropica, v. 175, p. 42-49, 2017. doi: 10.1016/j.actatropica.2016.10.022

OLIVEIRA, R. A. et al. Produção Orgânica de Citros no Rio Grande do Sul. EMBRAPA. Comunicado Técnico, 2011.

ORGANIS - Conselho Nacional da Produção Orgânica e Sustentável. Consumo de produtos orgânicos no Brasil. Relatório. 2017.

ORMOND, J.G. P. et al. Agricultura Orgânica: quando o passado é futuro. BNDS Setorial. Rio de Janeiro. 2002.

SOUSA, R. et al. Núcleo de Estudos em Agroecologia: a construção de uma (re) ação na Amazônia paraense. Cad. Agroecol., v.11, n.1, 2016.

TRICHES, R. M.; SCHABARUM, J. C.; GIOMBELLI, G. P. Demanda de produtos da agricultura familiar e condicionantes para a aquisição de produtos orgânicos e agroecológicos pela alimentação escolar no sudoeste do estado do paraná. Rev. Nera, n. 31, p. 91-110. 2016.

TUOMISTO, H. L. et al. Does organic farming reduce environmental impacts? A meta-analysis of European research. $J$. Environ.l Manag., v. 112, p. 309-320, 2012.

VIGANÓ, C. et al. Diagnóstico acerca da juventude rural na agricultura familiar: um estudo no município de Vitorino-PR. Cad. Agroecol., v. 14, p. 56, 2019.

VIGANÓ, C. et al. Autoconsumo e agroecologia: um retrato da agricultura familiar no município de Vitorino-pr. Anais do Seminário Internacional sobre Desenvolvimento Regional, 2019.

WANDERLEY, M. de N. B. O campesinato brasileiro: uma história de resistência. Rev. Economia Soc. Rural, v.52, p.25-44, 2014. doi: 10.1590/S0103-20032014000600002

WACHTER, J. M.; REGANOLD, J. P. Organic agricultural production: plants. Encyclopedia of Agriculture and Food Systems. p. 265-286, 2014.

$\mathrm{YU}, \mathrm{X}$. et al. Advances of organic products over conventional productions with respect to nutritional quality and food security. Acta Ecologica Sinica, v.38, n.1, p.53-60. 2018. doi: 10.1016/j. chnaes.2018.01.009. 
ZAMBERLAN, L. et al. O marketing de produtos orgânicos: um estudo exploratório a partir da opinião do consumidor.
In: ENCONTRO NACIONAL DE ENGENHARIA DE PRODUÇÃO. Rio de Janeiro, Brasil. 2008. 